\title{
DEL TOBOSO AL BARRIO DE LAS LETRAS: RECREACIONES DE DULCINEA EN MARÍA VELASCO Y CAROLINA ÁFRICA
}

\author{
Isabel Castells Molina \\ Universidad de La Laguna \\ icastell@ull.es
}

\section{RESUMEN}

Este trabajo se propone abordar el tratamiento del personaje de Dulcinea por parte de dos dramaturgas contemporáneas, Carolina África y María Velasco, en un proyecto colectivo titulado $A$ siete pasos del "Quijote». Para ello, analizaremos sus respectivas aportaciones, prestando especial atención a la mirada moderna desde la que se aborda uno de los temas principales de la novela cervantina: la oposición entre el mundo real y el ideal, a partir de la dualidad entre Aldonza y Dulcinea. Pretendemos también establecer un diálogo creativo entre las dos dramaturgas tanto con el inventor de la novela moderna como con otros autores de distintas épocas y contextos, desde una mirada interdisciplinar en la que intervienen otros lenguajes artísticos como el cine y la música. Asimismo, intentaremos también mostrar algunas relaciones entre las obras estudiadas en el trabajo y el resto de la producción de las dos dramaturgas.

Palabras clave: Dulcinea, Cervantes, María Velasco, Carolina África, A siete pasos del "Quijote», intertextualidad, recreación.

\author{
FROM EL TOBOSO TO EL BARRIO DE LAS LETRAS: RECREATIONS \\ OF DULCINEA IN MARÍA VELASCO AND CAROLINA ÁFRICA
}

\begin{abstract}
This paper aims to explore how two contemporary playwrights, Carolina África and María Velasco, address Dulcinea's character in a collective project called A siete pasos del Quijote. For this purpose, we will analyze their respective contributions, paying special attention to the modern way in which Africa and Velasco deal with one of the most important subjects in the Cervantes's novel: the real world and the ideal world opposition through the duality between Aldonza and Dulcinea. From an interdisciplinary approach, which includes other artistic languages such as cinema and music, we also intend to establish a creative dialogue between the two playwrights and the inventor of the modern novel as well as other authors. At the same time, we will try to show some connections between the pieces studied in this paper and the rest of both playwrights' works.

Keywords: Dulcinea, Cervantes, María Velasco, Carolina África, A siete pasos del "Quijote», Intertextuality, Recreation.
\end{abstract}

DOI: https://doi.org/10.25145/j.clepsydra.2020.19.02

Revista Clepsydra, 19; noviembre 2020, pp. 17-42; ISSN: e-2530-8424 


\section{1. iA LA CALLE CON CERVANTES!}

En noviembre de 2015, al calor de la conmemoración de los cuatrocientos años de la publicación de la segunda parte del Quijote, se desarrolló en el Barrio de las Letras de Madrid una interesantísima propuesta de teatro callejero en la que siete dramaturgos del panorama reciente rendían homenaje a nuestra primera novela moderna a través de una pieza breve que nos permitiera reconocer la actualidad del universo cervantino. En palabras de Alberto Conejero, encargado de la dramaturgia y de la presentación de la edición impresa de estos "pasos», «un universo que se nos muestra cada vez más contemporáneo, como si la voz de Cervantes se hiciera con el tiempo más radical y necesaria» (Conejero 10).

Por su parte, Jaroslaw Bielski, director del proyecto, declara que

se trata de una propuesta excepcional, arriesgada, casi quijotesca, en la que el teatro sale de su recinto cerrado y se arroja al misterio vivo de la calle [...]

un doble encuentro: por un lado, el de Cervantes con algunas de las voces más significativas de la dramaturgia española contemporánea y, por otro, el de los Quijotes y Dulcineas de hoy en día con los vecinos del barrio. Porque, aunque don Quijote no pasara nunca por Madrid, siete dramaturgos han imaginado y sońado quiénes serían hoy los personajes de las páginas por escribir del Quijote en nuestro presente y en algunos de los lugares más significativos del Barrio de las Letras'.

La referencia a "los Quijotes y Dulcineas de hoy en día» y al hecho de que diferentes dramaturgos hayan «imaginado y sońado" a un "Quijote en nuestro presente» nos indica, de antemano, que no estamos ante una adaptación moderna de la novela de Cervantes, al estilo, por ejemplo, de los montajes de la compañía Ron Lalá, que logra conjugar magistralmente el hipotexto cervantino con guiños muy reconocibles y humorísticos a la situación política y cultural del espectador, tanto en la impecable versión de la novela que supone En un lugar del Quijote (2005) como con la reunión de Entremeses y Novelas ejemplares en Cervantina (2015)2. Lo que pretenden Bielski y Conejero, por el contrario, es inventar y en ocasiones recrear las peripecias de los personajes cervantinos situándolas directamente en nuestro presente: no llevar a la escena las mismas aventuras escritas por Cervantes con una mirada contemporánea, sino imaginar cómo serían hoy, en el mundo cotidiano del espectador. No adaptación, pues, sino recreación. A este propósito ayuda enormemente el gran escenario natural que constituyen las calles madrileñas.

${ }^{1}$ Esta declaración procede de una entrevista de 2015 cuyo enlace incluimos en la bibliografía final.

${ }^{2}$ Para un panorama global de los distintos homenajes a Cervantes en el teatro contemporáneo, pueden verse los trabajos de María Fernández Ferreiro y López Mozo que reproducimos en la bibliografía final. 
Lo que encuentra, pues, quien pasea por el Barrio de las Letras o quien, como es nuestro caso, se dispone a leer estos "pasos» es, en efecto, un ejercicio de intertextualidad, tal y como lo entiende Genette:

Una relación de copresencia entre dos o más textos, es decir, [...] como la presencia efectiva de un texto en otro. Su forma más explícita y literal es la práctica tradicional de la cita [...] y menos literal, la alusión, es decir, un enunciado cuya plena comprensión supone la percepción de su relación con otro enunciado al que remite necesariamente tal o cuál de sus inflexiones, no perceptible de otro modo (Genette 10).

El palimpsesto cervantino, por seguir utilizando la terminología de Genette, se asoma en las situaciones recreadas, en el comportamiento o en los nombres de los personajes y, naturalmente, en citas directas y alusiones al texto de la novela, que no pasan inadvertidas ante el espectador, tanto si está familiarizado con el universo del Quijote como si lo conoce de un modo epidérmico.

Partiendo de estos planteamientos, el proyecto defiende, en primer lugar, un modelo de creación colectiva, estableciendo una fructífera conexión entre Cervantes y un variado elenco de dramaturgos. Asimismo, apuesta por la democratización de la literatura -al trasladarla a la calle-, por la intertextualidad y los lenguajes cruzados -al establecer un diálogo entre la novela, el teatro y otros géneros-, por la brevedad -al estar concebido como siete pequeñas piezas cuyo nombre remite al género popularizado en el siglo XVI por Lope de Rueda-y, en fin, por la inmediatez y la cercanía con el público, que se convierte en parte de la representación. Esta peculiar forma de abordar el espectáculo teatral se plantea, pues,

como aventura y viaje, como experiencia que se abre al paso de lo imprevisto y lo desconocido, que tiene algo que decir a un público que no es tal por necesidades pretenciosas [...]. El teatro en la calle, entonces, debe ser entendido no como un transferir del espacio exterior modos y personas del teatro, sino como una situación distinta del teatro (Crucianim y Falletti 15).

Y es justamente en esta «situación distinta» donde reside el principal interés de $A$ siete pasos del "Quijote», en la medida en que permite percibir a Cervantes, tristemente anquilosado en los circuitos académicos o en el a veces inaccesible pedestal de los clásicos, de forma familiar y cercana.

El recorrido por el conocido barrio madrileño que este proyecto de teatro callejero plantea es el siguiente:

- Prólogo: «La loa de Miguelillo», de Alberto Conejero (fachada del Teatro Español).

- «Encantados», de María Velasco (plaza de Santa Ana).

- «Patria chica, tierra ancha», de Pedro Cantalejo Caldeiro (plaza de Matute).

- "Eduardo y Luciana (El caballero de la encorvada figura)», de Carolina África (plaza de Matute).

- «Teme a tu vecino como a ti mismo!», de Lola Blasco (calle de Cervantes).

- «La gran burla», de Juan Mairena (cruce de calles de Cervantes con San Agustín). 
- "Qué hacer delante de un naufragio», de Sergio Martínez Vila (plaza de las Cortes).

- «Cierra los ojos, dame tu mano», de Íñigo Guardamino (plaza de las Cortes).

- Final, «La sonrisa de Miguelillo», de Alberto Conejero (plaza de las Cortes. Estatua de Cervantes).

En las páginas que siguen, nos proponemos analizar dos de estos «pasos», a cargo de dos representantes de la emergente dramaturgia femenina: María Velasco - «Encantados»- y Carolina África -«Eduardo y Luciana (El caballero de la encorvada figura)»-. Hemos decidido centrarnos en estas aportaciones femeninas al proyecto porque constituyen dos visiones complementarias del personaje de Dulcinea, en consonancia con la fluctuación entre realismo e idealismo que encontramos en Cervantes, lo que, esperamos, nos permitirá comprobar, una vez más, la apabullante actualidad de su proyecto narrativo.

Aunque profundizar en la complejidad y trascendencia de este singular personaje femenino ideado por Cervantes desbordaría el planteamiento y objetivo de este trabajo, intentaremos a continuación resumir someramente algunos aspectos que, de un modo u otro, recrean las dos dramaturgas que ahora nos ocupan.

\section{2. "DE ALTA CUNA Y DE BAJA CAMA": DULCINEA Y ALDONZA}

Dulcinea del Toboso se erige, desde nuestra perspectiva actual, como emblema de la invención en estado puro. Como bien sabemos, la aldeana manchega, convertida en excelsa dama merced a un arbitrario acto de voluntad de un hidalgo intoxicado por un exceso de ficciones, es el más importante personaje femenino in absentia de la literatura universal -Godot podría ser su contrapunto masculino-.

En efecto, Dulcinea, como tal, no aparece en ningún momento de la novela y solo se asoma ante el lector de manera indirecta, oblicua, siempre desde la perspectiva y la mirada del otro, generalmente masculino. Como acertadamente afirma Carmen Castro, las mujeres en el Quijote "llegan en general contadas, vivas en la historia que refiere de sí mismo otro personaje de la novela. [...] Y a Dulcinea nos la han contado de dos maneras: a lo Sancho, a lo caballero» (167).

La supuesta amada de don Quijote es, pues, una ficción en segundo grado, porque procede no solo de la imaginación del autor empírico -Miguel de Cervantes-, sino sobre todo de la de su enloquecido protagonista -don Quijote- y, en ocasiones, de la de otros personajes que aluden a ella con diferentes fines -Sancho Panza, especialmente, pero también la duquesa que aparece en la segunda parte de la novela, por ejemplo-.

Invención de una invención, Dulcinea constituye, así, uno de los ejes fundamentales de la parodia cervantina, que juega con diferentes representaciones de la figura femenina y, a través de ella, con modelos literarios opuestos. Siempre desde un lúcido y desafiante sentido del humor, Cervantes pone ante el lector dos Dulcineas: «La que merece ser señora de todo el universo» a la que dice idolatrar don Qui- 
jote (262) y la «moza de chapa, hecha y derecha y de pelo en pecho, [...] que puede sacar la barba del lodo a cualquier caballero andante» $y$ "tiene mucho de cortesana» que evoca Sancho (262); una perfecta, explícitamente ideal, que consume el tiempo «ensartando perlas» y otra pestilente, hiperbólicamente masculinizada, incluso animalizada, que gana su diario sustento «ahechando dos hanegas de trigo en un corral de su casa» (329). En estas dos visiones del personaje femenino, Cervantes opone, así, a la donna angelicata y a "la cortesana», a la dama y a la aldeana: a la representante, en fin, de toda una tradición neoplatónica y petrarquista, basada en la idealización de una figura femenina distante, ídolo de perfección, venerada y ausente, y a la mujer real, cotidiana, que en este caso aparece degradada y ridiculizada bajo el prisma de un expresionismo que parece adelantarse a la estética del esperpento.

Con gran maestría y atendiendo a los procedimientos instaurados en la novela caballeresca, Cervantes acude a la polionomasia, denominando de forma diferente a cada una de estas encarnaciones del personaje femenino: a la primera, otorga el eufónico nombre de Dulcinea, de resonancias musicales que evocan a grandes damas de la literatura española como la Melibea de La Celestina (Redondo 21) pero que, a juicio de Rafael Lapesa, posee también "resonancias de comicidad", sobre todo por el uso del genitivo "del Toboso» (217-218); mientras que la segunda es bautizada como Aldonza, nombre vinculado en la literatura áurea a la prostitución, como encontramos, por ejemplo, en la protagonista de La lozana andaluza, de Francisco Delicado.

Aldonza, tal y como la imaginamos por las descripciones de Sancho, está a años luz del recogimiento y recato que presupone don Quijote en Dulcinea. Recordemos, además, como indica Enriqueta Zafra, que en la época de Cervantes «se asocia con el comercio sexual a la mujer habladora y elocuente, la sensual, la andariega y la promiscua» (88), cualidades que muy bien podemos atribuir a la tosca aldeana del Toboso.

María Velasco, como veremos pronto, se ocupa en «Encantados» de Aldonza, la prostituta, bautizada como «DulCE»; mientras Carolina África nos presenta en «Eduardo y Luciana (El caballero de la encorvada figura)» a una peculiar y ausente Dulcinea de plasma.

Dulcinea es, en palabras de María Zambrano, «la inexistencia del amor en forma de mujer inexistente [...]; solo tenía que aparecer, que mostrarse, que ser llevada a la inexistencia del arte, lugar donde se es revelado sin ser poseído» (139). Es, pues, como decimos, pura literatura: una imagen arquetípica soñada desde una mirada masculina que se nutre de férreos tópicos culturales, un emblema de la creación misma.

La ironía de Cervantes consiste en mostrarnos cómo don Quijote la inventa, comportándose exactamente igual que un escritor ante su criatura literaria:

Y fue, a lo que se cree, que en un lugar cerca del suyo había una moza labradora de muy buen parecer, de quien él un tiempo anduvo enamorado, aunque, según se entiende, ella jamás lo supo, ni le dio cata dello. Llamábase Aldonza Lorenzo, y a ésta le pareció bien darle título de señora de sus pensamientos, y, buscándole nombre que no desdijese mucho del suyo y que tirase y se encaminase al de princesa 
y gran señora, vino a llamarla Dulcinea del Toboso, porque era natural del Toboso; nombre, a su parecer, músico y peregrino y significativo, como todos los demás que a él y a sus cosas había puesto (40).

Por esa misma razón, Cervantes pone en boca del autoproclamado caballero esta rotunda bofetada a toda la poesía petrarquista:

Y así, bástame a mí pensar y creer que la buena de Aldonza Lorenzo es hermosa y honesta; y en lo del linaje importa poco, que no han de ir a hacer la información dél para darle algún hábito, y yo me hago cuenta que es la más alta princesa del mundo. [...] Y para concluir con todo, yo imagino que todo lo que digo es así, sin que sobre ni falte nada; y píntola en mi imaginación como la deseo, así en la belleza como en la principalidad [...] (263-264).

En esta inmensa burla late, como decimos, la crítica cervantina hacia un modelo literario femenino completamente blindado en su época -a excepción, naturalmente, de la literatura satírica-y que él mismo cultivó tanto en su poesía como en su trayectoria narrativa desde La Galatea hasta el Persiles, con importantes ejemplos en las Novelas ejemplares.

La Aldonza transformada en Dulcinea no es, pues, más que un ingrediente necesario para la recién adquirida condición caballeresca del protagonista. Desde el abismo de la locura libresca, don Quijote decide amar a Dulcinea para apuntalar una vida concebida desde los parámetros del arte. Y por eso la afianza en su imaginación a la medida de su deseo. Un deseo del que su propio objeto permanece exento, ausente. $Y$ es esto justamente lo que nos permite vislumbrar claros indicios de una intención por parte del autor de ir más allá de la parodia, apuntando hacia una consideración de lo femenino tremendamente novedosa entre sus coetáneos. En palabras de Teresa Langle de Paz,

el elemento burlesco-grotesco que se introduce con el binomio Dulcinea-Aldonza [...] marca la pauta para plantear cuestiones de autoridad cultural, autoría, reflexiones sobre la historiografía, el dilema aristotélico de la veracidad del arte, etc. ¿Qué nos impide, pues, leer el texto también como una reflexión sobre la irrepresentabilidad de lo femenino dentro de los parámetros masculizantes [sic] del deseo y como «documento» de una historia literaria del feminismo, pero de un feminismo que, aunque no es historiografiable en el sentido tradicional tiene suma importancia para la comprensión profunda del texto? La amada, detonante, proyección y guía del viaje de búsqueda del sujeto masculino, contiene, como elemento de la representación, información capital sobre dos cuestiones: una, la imposibilidad conceptual de atender a las dimensiones más amplias del universo imaginístico y semiótico de lo femenino sólo desde una perspectiva histórico-literaria tradicional, y dos, la inminente necesidad de crear nuevas pautas para una historia literaria diferente que las incluya (242).

Reflexionar ahora sobre el supuesto o no feminismo de Cervantes -en caso, para empezar, de que aplicar al autor el término como tal no resulte anacrónicodesbordaría con creces el objetivo de estas páginas. Bastará con recordar que pode- 
rosos personajes como la pastora Marcela han devenido en iconos de autoafirmación femenina ${ }^{3}$, pero también que, como mencionábamos más arriba, en su novela póstuma encontramos, por ejemplo, a la cándida Lauristela, que en nada se aleja del modelo femenino imperante en la literatura áurea. Es, en nuestra opinión, arriesgado dilucidar la verdadera postura del autor con respecto a un tema ante el que, como en tantos otros - pensemos, por ejemplo, en la escabrosa cuestión religiosa-, se muestra ambiguo. Lo que sí es cierto -y es lo que nos interesa ahora- es que, entre burlas y veras, está cuestionando el espacio pasivo que se atribuye a la mujer dentro de un imaginario hecho a medida del hombre. Un hombre que necesita amar para sentirse vivo, para dar sentido a su existencia, con independencia de que el objeto de su amor exista o no más allá de su imaginación. Como bien explica el poeta Pedro Salinas en un fino ensayo sobre esta peculiar relación entre el hidalgo loco y la dama inventada, «la amada se ha transformado en el Amado. Dulcinea existe unida a Don Quijote, en él, solo en él. [...] De desear que exista la ha hecho existir» (121). Y es esto lo que nos mostrará, con notables diferencias, Carolina África, al escenificar la relación entre Eduardo y Luciana.

Concedamos, pues, que Cervantes cuestiona a través de Dulcinea un arquetipo femenino que es a la vez trasunto de toda una ética y una poética amatorias. Pero no perdamos de vista que lo hace desde la atalaya desmitificadora y nada trascendental de la parodia. No perdamos de vista a Aldonza, vinculada en la novela a un modo de representación opuesto al idealismo y que apunta claramente, como sugiere Rosa María Pereda, al centro mismo del esperpento:

[...] la cotidianeidad es fuente continua de desilusión. De frustración. [...] Lo deseado, esa felicidad sin nombre, no es de este mundo.

Este mundo es el Callejón del Gato. Ya sabemos, desde Valle, que la realidad española solo se puede narrar a partir de esas apariencias deformes, de esas manifestaciones y fenómenos fantasmales, soeces, exagerados, llenos de miseria y oprobio, moralmente infames -es decir, innombrables- y físicamente feos. Feos. Porque la belleza tampoco es de este mundo: campa, si puede campar algo en el ideal, junto con la bondad y la verdad, en ese lugar en que habita, fuera de nuestro alcance, la felicidad (436-437).

Aldonza es, pues, la grotesca prostituta que exhibe su encanto contrahecho en espejos cóncavos, en tanto que Dulcinea es el reflejo irreal de una hermosura artificial, modificada para ser contemplada en su pedestal inaccesible.

María Velasco nos muestra a Aldonza, la prostituta, emergiendo de las alcantarillas; Carolina África escribe el nombre de Dulcinea, la diosa, con luces cegadoras de neón.

3 Pensemos, por ejemplo, en sendos homenajes en el volumen colectivo La Cervantiada (Ortega) a cargo de Rosario Ferré y Julia Castillo y en trabajos como «Cuánto hablan las mujeres del Quijote: los casos de Marcela y Dorotea» (Redondo Goicoechea). 


\section{3. "ENCANTADOS», DE MARÍA VELASCO: ALDONZA, "ALCANTARILLERA DE SUEÑOS ADVERSOS"}

La primera representación de $A$ siete pasos del «Quijote» tras el «Prólogo» es precisamente el "paso" que nos propone María Velasco. «Encantados» constituye un claro ejemplo del proceso de recreación al que nos referíamos anteriormente, que queda perfectamente ilustrado en la acotación inicial:

Un hombre, seco y amojamado, permanece junto a una alcantarilla mal sellada de Santa Ana. Tiene remojados los bajos, la mirada en el infinito. De vez en cuando, da un trago a un «brik» de vino en una bolsa de plástico. Dulce llega corriendo como una exhalación, torciendo los tacones, con un generoso escote como «airbag» (Velasco 23).

La ascendencia quijotesca del protagonista masculino se muestra, como vemos, con la utilización de los mismos adjetivos, «seco y amojamado", que emplea Cervantes para caracterizar a su personaje en el primer capítulo de la segunda parte del Quijote, en tanto que el nombre de la protagonista femenina, DulcE, remite claramente a la dama inventada por el hidalgo y al estudio de Rafael Lapesa mencionado más arriba. El proceso de recreación de los personajes se advierte no solo en la descripción del lugar en que ambos se encuentran - «una alcantarilla mal sellada»-, sino en su caracterización a partir de dos rasgos que nos conducen claramente al feísmo de Aldonza: el atuendo de Dulce sugiere ya desde el principio que nos encontramos ante una desaliñada prostituta-recordemos que la aldeana cervantina tenía, según Sancho, aires de «cortesana»-, mientras el alcoholismo del personaje masculino, -que, como poco después sabremos, ostenta el nombre de Chicano, en clara correspondencia con el apellido del hidalgo Alonso Quijano-, queda metonímicamente descrito a través de ese «brik de vino». Dulce y Chicano, correlatos de Dulcinea y Alonso Quijano, habitan en nuestro tiempo y en un espacio sórdido y decadente, que nos recuerda a películas como La mujer del puerto (1991), de Arturo Ripstein, donde se nos ofrece, como en nuestro "paso», una imagen descarnada del sexo y de la vida prostibularia.

María Velasco entremezcla las palabras de Cervantes, tomadas en ocasiones de forma literal, con las suyas propias, convirtiendo su "paso» en un interesantísimo collage intertextual en el que encontramos tanto las citas directas como las alusiones al hipotexto de las que nos habla Genette.

Asistamos a la primera conversación entre los dos personajes:

Dulce.- (Descalzándose de un pie y masajeándolo). ¿Dónde te metiste, hideperro? Chicano.- (Sin mirarla). En el aliviadero.

Dulce.- ¿Qué?

Chicano.- (Reponiéndose antes con un sorbo de vino). La alcantarilla.

Los dos miran fijamente al agujero. Luego, Dulce examina a Chicano.

Dulce.- ¡Apestas!

Chicano.- Creí que era tu boca (23). 
Este inicial fragmento sitúa inequívocamente a los personajes en una atmósfera desagradable y disfemística, a años luz de esa «Edad de Oro» con la que soñaba don Quijote en uno de los episodios más célebres de la novela. La relación entre ambos, como vemos, no puede ser más opuesta a los códigos exquisitos del «amor cortés», manteniéndose desde el principio un pulso que queda establecido en la diferencia de registros lingüísticos. Observemos, en efecto, que Chicano utiliza un léxico culto e ininteligible para Dulce, lo que reproduce la contraposición de lenguajes que Cervantes despliega en los divertidísimos diálogos entre el caballero y su escudero a lo largo de toda la novela. Pero, mientras en la obra cervantina don Quijote se situaba claramente en un ámbito idealista y elevado frente a un Sancho pragmático y cotidiano de tono realista, en el texto de María Velasco los dos personajes pertenecen a un mismo entorno degradado que condiciona su aspecto y comportamiento. No existe, pues, en nuestro "paso» el planteamiento dialógico que, como demostró Bajtine, caracteriza a la gran novela cervantina. Por el contrario, Dulce y Chicano son prisioneros de un ambiente asfixiante claramente metaforizado por la alcantarilla, concebida como un «agujero» del que no pueden escapar. El léxico pretendidamente culto del protagonista masculino no es, pues, más que un guiño sarcástico que hace María Velasco para demostrarnos que nos encontramos ante un Alonso Quijano reflejado, como apuntábamos más arriba, en el espejo deformante del Callejón del Gato.

El juego intertextual al que nos invita María Velasco nos remite además, a través de la alcantarilla, a uno de los más atractivos y modernos episodios del Quijote: el descenso del protagonista a la mítica Cueva de Montesinos:

Dulce.- ¿Pero qué se te ha perdido a ti en ese pozo? ¿Sapos y culebras? Chicano.- ¿Pozo dices? (Grandilocuente). He hecho una gran experiencia. (Bebe). Me asaltó un sueño, y me entré a descansar un poco...

DulCE.- ¡Así tienes esos ojos de cocodrilo!

Chicano.- Y he visto cosas ahí, que no las ha habido ni habrá en la redondez de la tierra. Cuando quise darme cuenta, a doce o catorce pies, me hallé en las galerías, corredores, o como las llaman, de un palacio, que parecía el mismísimo Congreso de los Diputados.

Dulce.- ¡No me metas en dibujos!

Chicano.- Despabilé los ojos, y era entonces el que soy ahora, con la diferencia de que allí, a mesa puesta y cama hecha, fui servido a cuerpo de rey...

DulCE.- ¡Mira tus pantalones!

Chicano.- [...] Ancianos admirables me estrecharon la mano, y la flor y la nata y la espuma de hermosísimas hembras, vestidas de pelos y sortijas, muy de oro, y los dientes como perlas de sus orejas. ¡Chapadas!

Dulce.- (Escéptica). ¿Ah sí? ¿Y qué eran? ¿Princesas?

Chicano.- Más vale un zapato descosido suyo sucio, que tus barbas mal peinadas $(24-25)$.

Este diálogo constituye, como decimos, un homenaje directo a los capítulos XXII y XXIII de la segunda parte del Quijote en el que la prodigiosa cueva cervantina ha sido sustituida nada más y nada menos que por el edificio habitado por 
unos representantes de la sociedad -la clase política- irremediablemente alejados de nuestros protagonistas.

Chicano recrea las sensaciones relatadas en el hipotexto cervantino, al tiempo que la incredulidad de Dulce nos remite claramente a la actitud de Sancho y otros personajes que escucharon a don Quijote una vez finalizada su onírica experiencia. La dimensión intertextual de este fragmento se manifiesta no solo en la evocación general del episodio cervantino a través de la asociación entre la alcantarilla y la cueva, sino, muy especialmente, en la cita directa de fragmentos, diálogos y expresiones fácilmente localizables en los episodios del Quijote seńalados.

Pero, como decíamos al principio de estas páginas, no nos encontramos ante una adaptación de los personajes cervantinos a la escena contemporánea, porque Chicano no es don Quijote ni Dulce es Dulcinea o Aldonza: las criaturas de María Velasco son, si acaso, los descendientes lejanos de una estirpe literaria sugerida en el texto, pero se comportan como seres de y en nuestro tiempo, manteniendo, eso sí, intacto el ADN de sus antepasados de tinta.

De ahí que la reacción de Dulce nos remita también a otros episodios de la novela: aquellos en los que se hace referencia al supuesto «encantamiento» de Dulcinea, urdido, como sabemos, por Sancho Panza para intentar convencer a su amo de que su amada se había convertido en una rústica aldeana. La importancia del descenso a la Cueva de Montesinos reside justamente en el hecho de que por primera vez la imagen de la tosca Aldonza se superpone a la de la idealizada Dulcinea, iniciándose el progresivo declive del protagonista hasta su final retorno a la cordura, tras un largo periplo lleno de derrotas y desengaños. En su exquisito análisis de este episodio, advierte Juan Bautista Avalle Arce que

la situación no puede ser más grave, porque esta visión de Dulcinea encantada es el reconocimiento tácito, por parte de don Quijote, de su impotencia para reordenar el mundo. En sueños, su subconsciente ha traicionado la voluntariosa actitud que adopta en la vigilia. Los resortes de la voluntad ya no aciertan a integrar la evidencia visual con la representación ideal (201).

No resulta extraño que María Velasco se haya detenido en el único episodio de la novela en que don Quijote, encarado en soledad ante su propio mundo imaginario, percibe el mundo de forma degradada y grotesca, encontrándose con una maltrecha Dulcinea que incluso llega a pedirle dinero, en una atmósfera expresionista en la que Belerma, Montesinos y otros personajes del Romancero completan el elenco de un grotesco baile de máscaras. Un episodio, en fin, en el que, bajo la apariencia de una Dulcinea «encantada», asoma la caricatura de Aldonza, la aldeana rústica con trazas de prostituta.

Asistamos ahora a la reacción de Dulce, que nos remite a otro episodio de la novela cervantina: el de "La aventura del barco encantado", en el capítulo XxIX de la segunda parte:

Dulce.- ¡Qué máquina de disparates! ¡Acabóse el cuento! (Él da un trago). Tú estás alcoholizado. 
Chicano.- Alcoholizado, no: EN-CAN-TA-DO. (DulCE se echa a reir largamente). Y TÚ también.

Dulce.- (A carcajadas). ¿YO?

Chicano.- Como la madre que te parió. Encantada, mudada, trocada, trastocada... Dulce.- ¡Virgencita!

Chicano.- Estás encantada y vuelta en la más fea puta que imaginarse pueda, aunque a mí me parezcas la más hermosa criatura del mundo.

Dulce.- iii Hideputa!!!

Chicano.- De bien hablada en rústica, de ángel en diablo, de hermosa en fea (25).

En este diálogo, que tiene atisbos de ternura, se manifiesta la polarización entre el bien y el mal, el vicio y la virtud, la belleza y la fealdad, la educación y la grosería y, en fin, la santa y la prostituta, que viene pesando desde hace siglos en la representación de lo femenino: una polarización que ya enfocó Cervantes desde su maliciosa parodia y que se convierte en ácida crítica social en este texto de María Velasco.

A partir de aquí, todo el «paso» prolonga este duelo entre los personajes, en un lenguaje cruzado en el que, como hemos venido viendo, las palabras de Cervantes conviven con las de la propia María Velasco, creando un complejo entramado teatral que puede disfrutarse tanto si se reconoce la sombra -el palimpsesto, diría Genette- del hipotexto como si se percibe de forma literal. Y eso es así porque en este momento, tal y como perseguía el director del proyecto, Cervantes ha abandonado los anaqueles de las bibliotecas académicas para formar parte de unas reflexiones que aun hoy afectan a nuestra sociedad.

Es ahora, pues, cuando María Velasco nos habla de Cervantes, pero también de las relaciones entre el hombre y la mujer, de las diferencias sociales y, a través de todo esto, de ella misma y sus propias preocupaciones como ser humano y como dramaturga.

El extenso monólogo final de Dulce, del que reproducimos un fragmento, es, en este sentido, perfectamente coherente con el resto de la producción teatral de la autora y podría haber sido pronunciado por cualquiera de sus personajes:

Dulce.- (Reproduciendo un tema con su móvil). La mejor salsa del mundo es la hambre. [...] ¡Ay, bróder, si lo que este contó fuese de verdad! Que a veces pienso que nací en una cloaca, y he jalado aguas por estos ojos pa llenar el canal de Isabel II, III y IV. ¡Que no haya un terremoto que deje el canal a cielo abierto y nos abra en canal! ¡Ay, bróder, si fuera verdad! ¡Toda la vida pensando que el cielo estaba arriba! Pero si es que ya no se sabe ni qué es arriba ni qué es abajo ni las izquierdas ni las derechas. (Recapacitando). ¡Entonces las alcantarillas son como la valla de Melilla! ¡Muros en horizontal! Cuando me muera, no me den sepultura, que allá me seguirán follando los gusanos -oiga, está una en apuros y, en lugar de echarle una mano, le echan un polvo-. Arrójenme por el inodoro, y que la barca del Carón me lleve tuberías abajo, que yo ya sé lo que es el despeñarse, empozarse, hundirse en el abismo (27-28).

No hay duda alguna de que María Velasco, a través de su protagonista femenina, nos está hablando de forma elocuente no ya de Cervantes o de Dulcinea, sino 
del Madrid de 2015, con referencias a lugares concretos de la capital y, lo que es más importante, a temas propios de nuestra época y muy presentes en las nuevas generaciones, como la desazón e indefinición política o el siempre sangrante problema de la inmigración -que aborda, por cierto, la tercera dramaturga implicada en este proyecto, Lola Blasco, en «Temerás a tu vecino como a ti mismo»-, todo ello, una vez más, en un parlamento plenamente posmoderno en el que conviven el lenguaje soez con las referencias mitológicas y la reflexión existencial.

Este impresionante monólogo de Dulce nos remite, por tanto, a otros momentos similares en la trayectoria dramática de María Velasco, y es justo aquí donde el diálogo con Miguel de Cervantes se hace efectivo y real.

Recordemos ahora que la atención por parte de la autora hacia las prostitutas aparece ya en otras obras. Fuga de cuerpos, sin ir más lejos, empieza ya con una dedicatoria "A las chicas de la calle» y está plagada de monólogos de la protagonista con una fuerza dramática idéntica a la que acabamos de ver. Sirva este como ejemplo:

En la ciudad todo todo es seso -y yo empecé prostituyéndome en la calle Ilustració, con eso te lo digo todo- y el límite entre ligar y el puterío está ahí ahí. ¿Solo se llama prostitución cuando hay parné? ¿Y dejarse follar gratis, sin tarifa, por estar casá? ¿Tu sexualidad es menos liosa que la mía? Tú no eres una tonta del culo. Sabes como yo que ser moderna y, sobre todo, libre, es complicao, ¿o no? Porque vivimos rodeadas de monjas y jueces, pá muchos, tú y yo somos la misma cosa. [...] (Coge aliento). Y ahora, quien esté libre de pecado, que tire la primera gardenia... o me coma la almeja. Que las piedras están muy duras (Velasco, Fuga 62).

También en «Los dolores redondos», texto en el que cultiva un género tan recurrente en su obra como la autoficción y que lleva el significativo subtítulo de «Escritura, sexo y ambos dos», encontramos repetidas referencias a las prostitutas. Veamos este fragmento:

Cumplo mis obligaciones fiscales, las solidarias

Colaboro con una ONG, $10 €$ al mes, y trabajo

Con (mujeres biológicas y trans), prostitutas,

en Médicos del Mundo.

A ellas, a las Mujeres del mundo,

les repito, como el $\mathrm{ABC}$,

normas y conductas,

salubridad,

higiene social

que infrinjo sistemáticamente:

"Póntelo, pónselo».

«novios del Polígono, no» (Velasco, Los dolores 176).

Recordemos también que la trama de su famosa obra Si en el árbol un burka giraba también en torno a una orangutana obligada a prostituirse (y que, por cierto, se opone a una top model que decide ocultar su belleza: nuevo ejemplo de polarización entre lo bello y lo feo, y, en este caso, lo humano y lo animal, entre otros muchos temas en los que se reflexiona sobre lo femenino). 
Esta atención hacia las prostitutas es una manifestación del interés de María Velasco por los personajes marginados en general, como puede apreciarse también en obras como Nómadas no amados o Escenas de caza. Esta preocupación, sin embargo, no desemboca en excesos melodramáticos ni en bienintencionadas propuestas de redención. Muy al contrario, los personajes que desfilan por su dramaturgia se desnudan ante el espectador a través de parlamentos como los que acabamos de ver, en los que coexisten lo trágico con lo cómico hasta resolverse en una descorazonadora mueca de estupefacción.

Como bien afirma Víctor Sánchez Rodríguez en sus palabras introductorias a Escenas de caza:

Sus diálogos no renuncian al ingenio del cinismo, a lo patético de la ternura, ni a la depresión que oculta toda ironía. La comedia aflora ante la imposibilidad de tomarse este mundo demasiado doloroso, demasiado cruel, en serio. La comedia es, en las obras de María, una mezcla de humor pop-ibérico e ironía cabrona que hace un guiño constante al espectador, distanciándolo de aquello que está viendo (Velasco, Escenas 10).

La misma voz, amarga y trágica, que María Velasco concede a las prostitutas es la que se hace oír en «Dientes de leche», de Lina Meruane, aparecido en la interesantísima recopilación Microquijotes (EPPLE), a la que acudiremos en diferentes ocasiones, ya que comparte con $A$ siete pasos del Quijote dos importantes características: el diálogo intertextual con el universo cervantino y el formato breve $e^{4}$.

Asistamos ahora a un fragmento de un monólogo de la protagonista del microrrelato mencionado:

Sobre la burra el viejo se asoma, viene a echarme su mirada de hambre. [...] Aldonza, aúlla el viejo quiltro, Aldonza, sacudiendo las mechas como perro cautivo. No soy yo ésa: me llamo Lorenza, pero no se lo digo. Me agria la sangre que me hable sin apearse. Empuña un palo al que llama su lanza, y al acercar la punta al ruedo de mi falda le quedan las costillas al aire. En este ayuno nada importa: que no me hayan crecido tetas todavía, que todavía no sangre. Que todavía de noche me meta en la boca los dientes de leche, y los chupe, y chupe, y alguno me trague. [...].

Hambre es lo único que poseo: hambre. Por un mendrugo blando, por esas uñas negras gusto a salame te chuparía sin asco hasta los huesos.

[...]

Que no regrese el ingenioso a ojearme. Que cumpla su oferta, me digo, de andante, y se largue a pie por los caminos. Que me deje en prenda esta burra, que ya le exprimiré yo con mis encías las ubres y toda su sangre (77-78).

${ }^{4}$ En Microquijotes se reproduce, además de los que iremos mencionando en estas páginas, un significativo número de textos protagonizados por Aldonza-Dulcinea de los que no vamos a ocuparnos pero que resultan también muy interesantes: «La emperatriz del mundo se confiesa», de Luis Correa-Díaz (p. 50); «Don Aldonzo», de Juan Armando Epple (p. 53); «Don Quijote y Dulcinea», de David Lagmanovich (60), y «Epidemia de Dulcineas», de Marco Denevi (33). 
En esta estremecedora visión de la prostitución, Lina Meruane exacerba hasta el extremo el polo opuesto de la idealización libresca que constituye el objeto de la ironía cervantina, porque aquí Alonso Quijano se ha convertido en un anciano rijoso, un despiadado «viejo verde» cuya actitud hacia la endurecida Lorenzo incorpora al relato el escabroso tema de la pederastia y el abuso a las menores.

Lo que nos interesa aquí es observar cómo en este relato, al igual que en «Encantados», de María Velasco, se da voz a «las hijas de Lilith», por emplear la acertada expresión de Erica Murnay, y también a las herederas de Areúsa y Elicia, discípulas de la célebre alcahueta en La Celestina (1499), y de Aldonza, protagonista del descarnado y desinhibido retrato de la prostitución que es La Lozana andaluza (1528), de Francisco Delicado, y que, como comentamos más arriba, no por casualidad comparte nombre con la poco recatada aldeana cervantina.

Las putas tienen la palabra. Y están muy lejos de las amadas neoplatónicas. Muy lejos también de la femme fatale o de la vampira, porque el glamour y la fascinación que caracterizan a esos arquetipos femeninos estudiados por Murnay han sido suplantados por la marginalidad y el hambre. Dulce, en «Encantados» de María Velasco, es una drogadicta contrahecha y menesterosa, mientras que la Lorenza de «Dientes de leche» es una adolescente también acosada por la necesidad y la pobreza.

Nada tienen que ver, por tanto, estos personajes femeninos con las mujeres inaccesibles, nuevos iconos de belleza, que sonríen desde la lejanía de los anuncios publicitarios, ejemplificadas a la perfección por Carolina África en «Eduardo y Luciana».

Dulce y Chicano son, pues, dos claros representantes de un tipo de personaje marginal, que observa la sociedad desde una esquina sucia, y que si tienen opción de vislumbrar el cielo, es solo a través del turbio agujero de una alcantarilla. Un tipo de personaje que atrae a María Velasco, en su agridulce denuncia de una sociedad y un mundo que no son muy distintos a los que conocieron Cervantes y Valle-Inclán. Y para huir o descansar de ellos nacen los ideales inalcanzables, como la Dulcinea que sońó don Quijote desde la atalaya de su locura libresca. María Velasco hurta a sus personajes esta huida o redención a través de los espacios imaginarios; Carolina Âfrica sí ofrece al suyo esta posibilidad. Veámoslo.

\section{4. "EDUARDO Y LUCIANA (EL CABALLERO DE LA ENCORVADA FIGURA)», DE CAROLINA ÁFRICA: "DONDE HABITA EL OLVIDO»}

La propuesta de Carolina África, llena de compasión y ternura hacia su protagonista, parte de una identificación del tema principal del Quijote -la locura libresca- con una de las enfermedades que más preocupan a la sociedad actual: el alzhéimer. El protagonista de este "paso", EduARDo, pues, no modifica la realidad, como don Quijote, para adaptarla a unos modelos literarios, sino a causa de una enfermedad mental que le hace vivir anclado al pasado, impidiéndole asumir la muerte de su esposa, a quien confunde con la imagen de una mujer en un anuncio publicitario. Esta mujer es, por tanto, su particular Dulcinea; imagen ideal, inasible, inexistente, pero real para quien la contempla y desea. 
Asistamos a la acotación inicial de este "paso»:

Exterior de la calle Atocha. El público aguarda en la plaza Matute. En el balcón del segundo piso del número 2 hay un luminoso de un dentista que muestra la imagen de una mujer mayor, sonriendo, es un anuncio de dentaduras postizas. [...] A lo lejos, un anciano, Eduardo, camina de la mano con Miguel (África 37).

El «paso» se inicia con un diálogo entre dos personajes que parecen ser los hijos o parientes cercanos del protagonista -más adelante sabremos que, efectivamente, son la hija, el yerno y probablemente otro hijo-, quienes hablan de él en los mismos términos empleados en el Quijote por algunos personajes -como, por ejemplo, el cura, el canónigo, Sansón Carrasco o el mismo Sancho Panza-, que se preocupan por su modo particular de percibir la realidad y cómo afrontarlo.

Asistamos a un fragmento de esta conversación:

Consuelo.- (Mirando la pantalla del balcón con la imagen de la mujer mayor proyectada). ¡No me lo puedo creer! ¡También la han puesto aquí!

Adolfo.- ¿Qué pasa?

Consuelo.- (Refiriéndose a la imagen, señalándola). Pues que es la de los panfletos de la publicidad del dentista.

Adolfo.- ¿La que cree que es Luciana?

Consuelo.- Sí... (Mirando hacia atrás a MIGUEL y EDUARDO que vienen tras ellos). ¡Que no la vea, por favor...! Hoy estaba en todas las marquesinas del autobús y se ha tirado media hora hablando con una de ellas. Bueno... hablando solo.

Adolfo.- Pues mira, así se lleva una alegría.

Consuelo.- No, Adolfo. ¡Porque la mujer no le contesta y se pone muy nervioso! Vosotros seguid llevándole la corriente que vamos a acabar todos locos.

Adolfo.- Consuelo, si así está feliz, ¿qué vamos a hacer?

Consuelo.- ¡Es que no está más feliz! No soporto que le tratéis como si fuera bobo. Ahora todavía se le puede orientar "aquí y ahora" con un poquito de paciencia. Dice la doctora que hay que darle pistas de la realidad para que pueda venir por él mismo. Si le alimentáis los delirios va a ser peor (38).

Difícil es no acordarse, ante esta conversación, de las que mantienen en la novela cervantina los personajes que pretenden devolver a don Quijote a la realidad y, con ella, a la cordura representada por Alonso Quijano, «el Bueno»: así ocurre, por ejemplo, cuando le hacen creer que está encantado para conducirlo hacia la aldea dentro de una jaula, cuando Sansón Carrasco se disfraza de Caballero de la Blanca Luna para vencerlo en batalla y obligarlo a abandonar el ejercicio de la caballería, o, en fin, cuando el a veces malicioso Sancho construye mil y una patrañas para que su enloquecido señor acepte alguna cuestión pragmática. Se trata, en todos los casos, de «seguirle la corriente», adoptando su lenguaje y su misma percepción de la realidad.

La pieza de Carolina África también utiliza este recurso, pero anteponiendo la ternura a la, en ocasiones, cruel burla cervantina hacia su personaje. Porque, como decimos, Eduardo no está loco: está enfermo. No estamos ni de lejos afirmando que Cervantes ridiculiza a su personaje: muy al contrario, escribe para él una com- 
pleja peripecia que lo lleva mucho más allá de la simple locura y lo convierte en un icono literario eterno. Pero sí sostenemos que lo que en el Quijote se percibe como humorístico deviene trágico en "Eduardo y Luciana» y que, por más que el lector de Cervantes sufra con su personaje y lamente la final claudicación de don Quijote en Alonso Quijano, la novela nos regala impagables momentos cómicos, algo que difícilmente sucede en la obra de Carolina África, a la que el espectador asiste con tristeza y angustia, la misma que rodea a la terrible enfermedad mental que en ella se retrata.

La trama de "Eduardo y Luciana» constituye, así, una bella historia de amor senil y nos recuerda a El hijo de la novia (2001), ya que nuestro "paso" y la película de Juan José Campanella tienen en común el hecho de que uno de los enamorados vive enajenado de la realidad y los familiares que lo rodean hacen lo posible, metiéndose en su mundo, para complacerlo.

La desubicación del protagonista de «Eduardo y Luciana» es, a causa de su enfermedad, absoluta y se traduce también en su desorientación espacial, confundiendo lugares del pasado -los bares, las tiendas- con lo que son actualmente, algo que sirve también a Carolina África para reflejar en su breve pieza la transformación e incluso el deterioro que ha ido sufriendo el centro de la capital madrileńa. Sirva como ejemplo esta conversación entre padre e hija:

Consuelo.- Ya no hay tienda de confección, papá. Mira, es un bazar chino. ¿¿o ves? Vamos.

EdUARDO.- (Mira el bazar chino con extrañeza). ¿Chino? (Rompiendo completamente de actitud y muy resuelto). Félix tiene que estar en La Filmo ihombre! Vamos a pasar a tomar algo, que os invito yo.

Consuelo.- A ver, papá. Mírame. Ya cerró La Filmo hace años, papá. ¿̨e acuerdas? ¿No te acuerdas de que Félix lo arrendó y mientras hacían la reforma hubo un incendio? ¿No te acuerdas? ¡Se quemó todo! (Señalando el local y asegurándose de que EDUARDO no vea la imagen proyectada).

EduARdo.- (Desorientado, haciendo esfuerzo por recordar). Ayyy el incendio... ¿Por qué está aquí toda esta gente? (Los mira sonriente). «A fuego y a boda, va la aldea toda» (40).

Junto a la desorientación espacial, volvemos a observar la rotunda confusión temporal, que lleva al protagonista a mezclar sucesos del pasado con el presente, lo que, como es habitual en quienes padecen alzhéimer, provoca situaciones de intensa angustia. Justo esto es lo que le ocurre a EDUARDo cuando la enfermedad le hace creer que su esposa muerta está en peligro por el incendio del que se hablaba en el fragmento transcrito:

Eduardo.- ¿Dónde está Luciana? (Sacando del bolsillo el panfleto del dentista con la foto de LUCIANA. Al público). ¿Han visto a mi Luciana? ¿La han visto? (A ADOLFO). ¿Dónde está tu madre?

[...]

¿Le ha pasado algo a mi Luciana? (Dubitativo, perdido). ¿Por qué han venido todos estos? ¿Qué pasa? ¿Qué hacemos aquí? (Se pone muy nervioso, desorientado, confuso). ¿Dónde está Luciana? 
Consuelo.- Papá... Papá, mírame... Papá... (No sabe qué decir). Mamá... ya no... Adolfo.- ¡Consuelo, a ver qué vas a decir!

Eduardo.- ¿Qué pasa Consuelo? ¿Qué pasa? ¿Qué le ha pasado a tu madre? (Muy nervioso, casi temblando).

Consuelo.- Nada, papá. (Silencio). No pasa nada. (Sonriendo pero a punto de llorar). Ven aquí... Que Mamá... mamá... te quería organizar una fiesta, ¿ves? Pero era sorpresa (40).

La compasión, el cariño y, especialmente, la incapacidad para gestionar la situación consiguen que hasta la hija, la única que al principio de la pieza se mostraba como representante de la realidad y la cordura, acabe prolongando el juego de piadosas mentiras. Y es ahora cuando Luciana se convierte en Dulcinea, una Dulcinea a la que nuestro Quijote de la desmemoria adora desde la distancia. Una Dulcinea de neón, bella, perfecta y, sobre todo, viva para quien la contempla tras haberle otorgado, con la complicidad de los hijos, la identidad de su esposa fallecida:

EduARDo.- ¿Y dónde está tu madre?

Consuelo.- Pues quería darte una sorpresa... pero... Mira... (Le gira y le muestra la pantalla con la imagen fija de LUCIANA).

Eduardo.- ¡Luciana! ¡Luciaana! Pero cómo... pero qué... ¡Pero bueno!

Consuelo.- ¿'Has visto? Le ha ayudado Miguel a organizarlo todo, ¿has visto qué bonito, papá?

Eduardo.- ¡Luciana! Pero ¿qué haces allá arriba, mujer?, ¡baja!

Consuelo.- Con lo que les ha costado prepararlo, déjala ahí, que está muy guapa $(42-43)$.

Si nos fijamos en la acotación situada en la primera intervención de CoNsUElo en este fragmento, observamos que la autora nos está introduciendo directamente en la perspectiva de EDUARDo, ya que no se ha referido a la mujer de la pantalla como a una anónima modelo publicitaria, como sí hizo en la primera acotación transcrita más arriba: muy al contrario, le ha asignado ya la personalidad y el nombre de la difunta esposa que está viendo el protagonista. De este modo, nosotros, como el resto de personajes cómplices, estamos situados también en ese prolongado plano subjetivo desde el que EDUARDo interpreta lo que ve en la pantalla. A esto nos referíamos cuando comentábamos que Carolina África es más compasiva con su personaje que Cervantes, porque, como bien sabemos, en ningún momento el lector de la novela vislumbra el menor atisbo de Dulcinea, a la que percibe sin excepción alguna como una invención del caballero enajenado. Carolina África, sin embargo, nos permite ver a LUCIANA con los ojos de EDUARDo, poniéndonos a su nivel y suprimiendo, así, esa superioridad del lector/espectador hacia un personaje considerado loco, actitud de superioridad que, como sabemos, es imprescindible para producir el efecto cómico.

A partir de este momento, la pantalla, como representación metafórica de la amada, se convierte en un personaje más de este "paso»:

Eduardo.- ¡Pero baja, mujer! Mira que eres. ¿Eh, Luciana? Y no sueltas prenda... ¡Luciana! ¿Para qué has montado todo este jaleo, mujer? 
Consuelo.- Déjala, que lo ha hecho porque ha querido.

Eduardo.- Pero si es que no tenías que hacerlo. Que yo soy más de que estemos en casa... Nos tomamos un vino y nos bailamos una de Manolo Escobar.

Consuelo.- ¿Cuál te gusta de Manolo Escobar?

Eduardo.- (Contestando como si lo hubiera dicho la pantalla). Pues la del carro, o la otra que te gusta a ti Luciana... ¡Luciana! ¿Cuál es la que te gusta a ti de Manolo Escobar? Qué jodía la tía que no suelta prenda...

Consuelo.- Ni se compra ni se vende...

Adolfo.- Miguel, ¿puedes ponerla al teléfono? (MIGUEL la pone) (43).

En este "como si lo hubiera dicho la pantalla» recae, en efecto, la inteligente utilización de elementos propios de la vida actual en esta pieza, reforzada, además, con la función del teléfono móvil para introducir la banda sonora.

Asistamos ahora al final de este "paso»:

Consuelo.- Papá, ¿bailas conmigo y que nos vea mamá?

Eduardo.- Pues claro... (Empieza a sonar "Ni se compra ni se vende» y bailan en la plaza, invitan a bailar a los asistentes, la música suena del móvil y luego más fuerte por los altavoces de la microfonía. EDUARDO mira la pantalla). Dice tu madre que no lo haces mal del todo.

Consuelo.- Ya la oigo, papá... ya la oigo. (Siguen bailando y la imagen de la pantalla empieza a hablar. Es como si solo la oyera EDUARDO aunque el resto le sigue el juego). Luciana en la Pantalla.- Pues no, no lo hace del todo mal. Pero anda, Eduardo, estírate un poco que te sale chepa. Ten cuidado y no la pises.

EduARDo.- Lo intento, lo intento.

Luciana en la pantalla.- Manolo Escobar no está mal, pero yo soy más de Antonio Molina o Juanito Valderrama.

Esto podría decirlo también CONSUELO, simultáneamente con el video. Algunas frases sí y otras no. Como si en realidad lo dijera CONSUELO pero EDUARDO cree que es LUCIANA desde la imagen.

EduARDo.- ¡Qué jodía eres, Luciana!

Luciana voz.- Y todos nosotros a bailar... que «en esta vida loca, uno es el que baila y otro es el que toca” ¡Cómo le cuesta a la gente arrancarse! Vamos, no os quedéis como pasmarotes y bailad. ¡Vamos! Eduardo... ¡No te encorves! ¡Estírate, Eduardo, estírate!

Eduardo.- Ya me estiro, ya, ya me estiro.

Todos bailan, Luciana también desde la pantalla, hasta que acaba la canción de Manolo Escobar. La imagen se queda fija nuevamente. Oscuro (45).

La utilización de recursos audiovisuales dota, como vemos, de gran interés a «Eduardo y Luciana» y se pone al servicio del gran tema de la obra cervantina. En el Quijote, en efecto, conviven distintos niveles de ficción, desde las invenciones paralelas de distintos personajes (Dulcinea es la principal de ellas) hasta la continua utilización de la mise en abyme (relatos intercalados, la novela dentro de la novela, personajes lectores y personajes leídos, etc.), logrando que el concepto de «realidad» acabe resultando difuso y problemático.

Carolina África, a través de la incorporación de un elemento audiovisual, crea una ficción dentro de la ficción mayor que es «Eduardo y Luciana», permi- 
tiendo un interesante diálogo entre lo que se ve en la pantalla y lo que ocurre en el nivel de los actores y el propio público. Al dotar, además, a su particular Dulcinea de voz propia y hacerla interactuar con personajes y espectadores, diluye, como ocurre en la novela cervantina, las fronteras entre lo imaginario y lo real, situando así a la obra en una nebulosa metaficcional. Si los asistentes al espectáculo y, con ellos, los lectores acaban bailando al son de Luciana, ¿no será que la mujer que habla desde la pantalla es real? ¿Compartimos, pues, todos nosotros la misma percepción de Eduardo? ¿Somos parte del mismo juego piadoso?

La propia autora explica lo que se propuso al concebir su personal aportación a este homenaje contemporáneo a Cervantes:

Me interesó el mundo de la fantasía y la realidad como la ve el Quijote y cómo choca con la realidad del resto. Quería buscarlo en un Quijote contemporáneo, que por sus propias circunstancias percibe el mundo de una manera diferente. Ve sus propios gigantes en vez de molinos o busca su propia Dulcinea, y la diatriba es si lo mejor es traerlo a la realidad o dejarle que siga en ese mundo si ello puede evitarle sufrimiento5.

Es el momento ahora de relacionar las propuestas de Carolina África con las de otros autores. Para ello, regresemos, en primer lugar, a la antología Microquijotes anteriormente mencionada, esta vez para recordar el célebre microrrelato de Juan José Arreola «Teoría de Dulcinea», que, a través de la oposición entre los "vagos fantasmas femeninos» y "una mujer de carne y hueso», insiste una vez más en el conflicto entre lo ideal y lo real:

En un lugar solitario cuyo nombre no viene al caso hubo un hombre que se pasó la vida eludiendo a la mujer concreta.

Prefirió el goce manual de la lectura, y se congratulaba eficazmente cada vez que un caballero andante embestía a fondo uno de esos vagos fantasmas femeninos, hechos de virtudes y faldas superpuestas...

[...]

En el umbral de la vejez, una mujer de carne y hueso puso sitio al anacoreta en su cueva.

$[\ldots]$

El caballero perdió la cabeza, pero lejos de atrapar a la que tenía enfrente, se echó en pos, a través de páginas y páginas, de un pomposo engendro de fantasía.

[...]

$\mathrm{Al}$ volver de la búsqueda infructuosa, la muerte le aguardaba en la puerta de su casa. [...]

Pero un rostro polvoriento de pastora se lavó con lágrimas verdaderas y tuvo un destello inútil ante la tumba del caballero demente (25).

${ }^{5}$ Véase en la bibliografía final el enlace a entrevista 1. 
Veamos también otros microrrelatos incluidos en la antología de Epple en los que se aborda la misma temática. Empecemos por el titulado justamente «Dulcinea", donde se invierte la capacidad de fabular y adorar un ideal inexistente, atribuyéndosela a Aldonza:

Vivía en El Toboso una moza llamada Aldonza Lorenzo... Como hubiese leído novelas de caballería, porque era muy alfabeta, acabó perdiendo la razón. [...] Se inventó a un galán a quien dio el nombre de don Quijote de La Mancha (Denevi 29).

En el siguiente microrrelato, que reproducimos completo y que lleva el significativo título de «La mujer ideal no existe», el mismo autor fulmina el mito de la amada inventada:

Sancho Panza repitió, palabra por palabra, la descripción que el difunto don Quijote le había hecho de Dulcinea.

Verde de envidia, Dulcinea masculló:

-Conozco a todas las mujeres del Toboso. Y le puedo asegurar que no hay ninguna que se parezca ni remotamente a esa que usted dice (Denevi 31).

Este último ejemplo ilustra y condensa, en apenas dos párrafos, el gran tema cervantino que venimos tratando. Recordemos que la gran ironía de Cervantes consiste en la paródica circunstancia de que su personaje construye un amor ideal, neoplatónico, completamente al margen de la mujer «real» que supuestamente lo inspira. Aldonza ignora que es Dulcinea porque, como bien nos indica Denevi en este microrrelato, los mundos de lo real y de lo ideal discurren de forma independiente e incompatible. Así las cosas, Dulcinea -la de Cervantes y la de Denevi- es de la misma estirpe que Eugenia, la mujer a partir de la cual Augusto Pérez, el protagonista de Niebla (1914), de Miguel de Unamuno, «inventa» un amor para sentirse vivo. $\mathrm{Y}$ ambas son tan difusas y evanescentes como ese halo de luz al que cree amar Garcés, en "El rayo de luna» (1871), de Gustavo Adolfo Bécquer. Algo muy similar ocurre en Don Quijote (1957), la versión de la novela cervantina a cargo del realizador soviético Grigor Kozinstev, donde vemos a una aldeana completamente inconsciente de que le ha sido otorgada la identidad de Dulcinea, a quien, como en el microrrelato que analizamos, envidia en secreto. No estamos, pues, ante amores realizados ni correspondidos: estamos ante enamorados del amor o de la propia idea del amor. Ante hombres que aman su idea de la mujer, pero no a la mujer misma.

Por su parte, en "Habla Aldonza», David Lagmanovich da un paso más, otorgando a la aldeana la oportunidad de establecer distancias y encararse con la mujer ideal que nos ocupa, a la que interpela directamente:

Señora mía Dulcinea, os digo que no. Jamás, ni siquiera en sueños, osaría ocupar el lugar de Su Señoría [...].

Mi mundo, señora, es mucho más humilde: bien sé que las damas y caballeros lo desprecian. En este mundo mío me tocó entretener a mi vecino, el hidalgo Alonso Quijano, quien en las noches solía allegarse a mi lecho para hacer conmigo su voluntad como los hombres suelen (62). 
La dama inalcanzable y la aldeana de carne son, como vemos, excluyentes. Y lo interesante de este microrrelato es que a la segunda se le otorga una voz propia para expresarlo.

Regresando a Carolina África, observemos cómo se hace eco en «Eduardo y Luciana» de todas estas perspectivas, llevándolas, a través del recurso de la pantalla, aún más lejos, porque no se trata solo de que la figura femenina del anuncio ignora que alguien la considera su amada: es que directamente no existe como mujer. Es solo una imagen, un fantasma de neón, similar al que aparece en Quijote, de Salman Rushdie (2020), otra interesantísima recreación del universo cervantino en nuestro mundo actual, protagonizada por un anciano intoxicado por la ficción televisiva que encuentra en una carismática presentadora a su particular Dulcinea catódica ${ }^{6}$.

Como hicimos en el caso de María Velasco, ocupémonos ahora, también brevemente, de establecer una conexión entre «Eduardo y Luciana» - con su palimpsesto cervantino- y el resto de la producción dramática de Carolina África.

Nada mejor para este propósito que leer sus propias declaraciones:

Hay grandes temas universales que se repiten en mis obras como el amor, la amistad o la familia, tanto la que no elegimos como la que sí, que son los amigos. De temática hablo del alzheimer como homenaje a mis abuelas que padecieron demencia senil. En Vientos de Levante también he hablado de la ELA7.

En Verano en diciembre, en efecto, aparece el personaje de la abuela, quien, tras mostrar continuamente su absoluta desorientación mental, acaba siendo recluida en una residencia; mientras que en Vientos de levante se desarrolla esta conversación que tanto nos recuerda a nuestro "paso":

AinhoA- (A Pepa).- ¿Está bien seguirles la corriente?

Pepa.- La teoría dice que no hay que reforzarles el pensamiento delirante pero si su delirio les salva del sufrimiento, yo no voy a cargarme eso (ÁFrICA, Vientos 72).

En esta misma obra, por otra parte, nos encontramos con personajes que creen comunicarse con la pantalla del televisor:

Pepa.- Hay tiempo para todo. ¿Quieres pasar dentro y te presento a algún loquito? AinhoA.- Vale.

Pepa.- Mira, esta es la sala de espacios comunes, aquí el que quiera puede ver la tele. Bueno, el que quiera y el que pueda, que no todos pueden.

AinhoA.- ¿Por qué?

${ }^{6}$ Aunque el planteamiento de esta novela comparte con los ejemplos que ahora nos ocupan el hecho de valerse del recurso al mundo audiovisual para componer a una Dulcinea contemporánea, el desarrollo de la trama difiere notablemente, porque Rushdie decide, en un momento determinado de la novela, entrecruzar las trayectorias del sujeto deseante y el objeto deseado en un sorprendente destino común.

7 Veáse entrevista 2 en la bibliografía final. 
Pepa.- Porque se alteran, algunos creen que les habla a ellos directamente la televisión y entran en paranoia o alucinación y no pueden verla (África, Vientos 33).

Además, en la acotación final se sugiere, como acabamos de ver en nuestro "paso», la utilización de elementos audiovisuales:

(Vemos a Ainhoa, puede estar en el tren con el cuaderno que le ha regalado JuAN o en un escritorio en primer término como si estuviera en su casa de Madrid escribiendo en un ordenador. Si hay ciclorama podría escribirse sobre él VIENTOS DE Levante. Termina el Pequeño Vals Vienés de Silvia Pérez Cruz y empieza Que me van aniquilando también de Silvia Pérez Cruz. Esta es la letra que se escuchará y durante el minuto que dura la canción se sucederán pequeñas estampas escenificadas) (ÁfricA, Vientos 117).

El hecho de entrecruzar la palabra, la música y la imagen que acabamos de ver en Carolina África y en el Quijote de Salman Rushdie es frecuente en el teatro contemporáneo y, salvando las grandes diferencias, nos recuerda a las producciones de la compañía La Cubana, con los continuos saltos entre la pantalla, el escenario y el patio de butacas, o a un montaje como Ana (2018), de Irma Correa, un muy moderno y actual homenaje a Benito Pérez Galdós.

Emmanuelle Garnier menciona, por su parte, una nómina de dramaturgas que se sirven igualmente de este procedimiento:

Un gran número de obras actuales de mujeres entrelazan al hilo de este lenguaje verbal, imágenes grabadas o proyectadas directa o indirectamente (Memoria de Yolanda Pallín), a veces incluso imágenes de textos (Pared de Itziar Pascual), canciones (Como si fuera esta noche de Gracia Morales, Pared, Las voces de Penélope, Père Lachaise de Itziar Pascual), diversas grabaciones, en particular las de contestadores telefónicos... (245-246).

Las fronteras entre el cine y el teatro ya se han diluido e incluso las nuevas tecnologías -recordemos el uso del teléfono móvil como parte esencial de la banda sonora de «Eduardo y Luciana» y «Encantados»- se convierten en una importante herramienta diegética ${ }^{8}$.

Todo esto nos conduce a una jugosísima interferencia de lenguajes, de temas, de tonos, de iconos. En el "paso" que nos ocupa, por ejemplo, el hecho de hacer convivir a Cervantes - autor de la más encumbrada novela universal- y a Manolo Escobar -el rey indiscutible de las verbenas- en un mismo contexto es altamente significativo. Y no es la primera vez, por cierto, que Carolina África incorpora en una obra suya canciones muy conocidas de la llamada «música ligera»: en Verano

${ }^{8}$ En un teléfono móvil reside toda la diégesis de una obra de Juana Escabias significativamente titulada WhatsApp (2019), donde a través de un hilo de chat se reconstruye magistralmente la relación entre una joven y su novio maltratador. Una vez más, las nuevas tecnologías se convierten en el eje de la dramaturgia. 
en diciembre se menciona a Rafaela Carrá, mientras que en Vientos de levante resuenan los ecos de Raphael y Los Panchos. No olvidemos tampoco que las canciones de Paquita la del Barrio, a medio camino entre el melodrama y el más ácido humor involuntario, resuenan en Fuga de cuerpos, de María Velasco.

Las dos dramaturgas, desde su personal concepción de la creación dramática, han rendido homenaje a la peculiar criatura cervantina en la que, como hemos venido viendo, se reflejan los dos polos opuestos de la representación de la figura femenina mediante los cauces del realismo y la idealización.

Si retomamos ahora las iniciales palabras de Jaroslaw Bielski, en las que manifestaba su intención de mostrar al público contemporáneo «los Quijotes y Dulcineas de hoy en día", podemos concluir que María Velasco y Carolina África, cada una con su propio lenguaje y en perfecta sintonía con otros autores mencionados en las páginas precedentes, han logrado con creces este propósito.

«Encantados», con su Aldonza de alcantarilla, y «Eduardo y Luciana», con su Dulcinea de plasma, nos han regalado, en efecto, dos representaciones críticas, necesarias, de un personaje universal. Y lo han hecho a través del cuestionamiento de tópicos y arquetipos, prolongando la misma mirada, escéptica y confrontadora, desde la que Cervantes encaró los molinos y los gigantes, las damas y las putas, de su propia época. 


\section{REFERENCIAS BIBLIOGRÁFICAS}

Libros, ARTÍ́CULOS Y ENLACES WEB

ÁfrICA, Carolina [entrevista 1]. http://www.madridteatro.eu/index.php?option=com_content $\&$ view=article\&id=4161:a-siete-pasos-del-quijote-j-bielski\&catid=314:entrevistas\&Itemid=286.

ÁfrICA, Carolina [entrevista 2]. https://www.diariodecadiz.es/ocio/felicidad-incierta-ries-lloras-obras_0_1156984325.html.

ÁfrICA, Carolina Verano en diciembre. Madrid: INAEM, 2013. http://www.contextoteatral.es/veranoendiciembre.html.

África, Carolina Vientos de levante. Madrid: INAEM, 2018. Disponible en pdf: https://www.google.

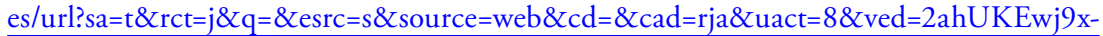
73d0_7qAhVC2-AKHV0oA_QQFjAAegQIBBAB\&url=https\%3A\%2F\%2Fmuestrateatro.com\%2Farchivos\%2FVientos-de-levante.pdf\%3Fdate\%3D2015-01-28\&usg=AOvVaw17-FO9ZLezPqN0r0I10mnY.

África, Carolina «Eduardo y Luciana», en Conejero, Alberto (ed.), A siete pasos del "Quijote», Madrid: Madrid Destino, 2017, pp. 37-45.

Arreola, Juan José. «Teoría de Dulcinea», en Epple, Juan Armando, Microquijotes, Barcelona: Thule Ediciones, 2005, pp. 23-25.

Avalle Arce, Juan Bautista. Don Quijote como forma de vida. Valencia: Fundación Juan March-Castalia, 1976.

Bajtine, Mihail. La cultura popular en la Edad Media y en el Renacimiento. Madrid: Alianza Editorial, 1990.

BÉCQuer, Gustavo Adolfo. «El rayo de luna». Rimas, Leyendas, Cartas desde mi celda, ed. de P. Palomo. Barcelona: Planeta, 1982.

BIELSKI, Jaroslaw [entrevista]. https://www.teatroateatro.com/estas-a-siete-pasos-del-quijote/.

Castro, Carmen. «Las mujeres del Quijote. Personajes femeninos en Cervantes», en Rubio, Fanny (ed.), El «Quijote» en clave de mujerles, Madrid: Editorial Complutense / Instituto de Investigaciones Feministas, 2005, pp. 165-206.

Conejero, Alberto (ed.). A siete pasos del «Quijote». Madrid: Madrid Destino, 2017.

Cervantes, Miguel de. Don Quijote de la Mancha, ed. de Martín de Riquer, Barcelona: Planeta, 1980.

Crucianim, Fabrizio y Falletti, Clelia (eds.). El teatro de calle. Técnica y manejo del espacio, México: Gaceta, 1992.

Denevi, Marco. «Dulcinea del Toboso», «Realismo femenino», «La mujer ideal no existe», en Epple, Juan Armando, Microquijotes, Barcelona: Thule Ediciones, 2005, pp. 29-33.

Escabias, Juana. Cartas de amor... después de una paliza. La puta de las mil noches. WhatsApp, edición de Francisco Gutiérrez Carbajo. Madrid: Cátedra, 2019.

Fernández Ferreiro, María. «Adaptaciones teatrales del Quijote (siglos xx-xxi). Selección de un corpus», en «Scripta manent». Actas del I Congreso Internacional Jóvenes Investigadores Siglo de Oro.

Garnier, Emmanuelle. Lo trágico en femenino. Dramaturgas españolas contemporáneas. Bilbao: Artezblai, 2011. 
Genette, Gerard. Palimpsestos. La literatura en segundo grado. Madrid: Taurus, 1989.

(JISO 2011), ed. C. Mata Induráin y Sáez. Pamplona, A.J. Servicio de Publicaciones de la Universidad de Navarra, 2012 (Publicaciones digitales del GRISO), pp. 185-194.

Langle de Paz, Teresa. «La voz indivisible. Dulcinea y el feminismo», en Rubio, Fanny (ed.), El «Quijote» en clave de mujerles, Madrid: Editorial Complutense / Instituto de Investigaciones Feministas, 2005, pp. 233-255.

Lagmanovich, David. «Habla Aldonza», en Epple, Juan Armando, Microquijotes, Barcelona: Thule Ediciones, 2005, pp. 62.

LApesa, Rafael. «Aldonza, Dulce, Dulcinea». De la Edad Media a nuestros días. Estudios de historia literaria. Madrid: Gredos, 1971, pp. 211-218.

López Mozo, Jerónimo. «La narrativa de Cervantes. Reescrituras españolas para la escena (19502014)», en http://teatro.es/contenidos/donGalan/donGalanNum5/.

Meruane, Lina. «Dientes de leche», en Epple, Juan Armando, Microquijotes, Barcelona: Thule Ediciones, 2005, pp. 77-78.

Murnay, Érika. Las hijas de Lilith. Madrid: Cátedra, 1990.

Ortega, Julio (ed.). La cervantiada. Madrid: Ediciones Libertarias, 1993.

Redondo, Augustin. «Del personaje de Aldonza Lorenzo al de Dulcinea del Toboso: algunos aspectos de la invención cervantina». Anales Cervantinos, xxi (1983), pp. 9-22.

Redondo Goicoechea, Alicia. "Cuánto hablan las mujeres del Quijote: los casos de Marcela y Dorotea». El "Quijote» en clave de mujerles. Madrid: Editorial Complutense / Instituto de Investigaciones Feministas, 2005, pp. 445-460.

Rushdie, Salman. Quijote. Barcelona: Seix-Barral, 2020.

Salinas, Pedro. «La mejor carta de amores de la literatura española», en Haley, George (ed.), El Quijote, Madrid: Taurus, colección «El escritor y la crítica», 1980, pp. 109-121.

Unamuno, Miguel de. Niebla. Edición de Germán Gullón. Madrid: Espasa-Calpe, 1975.

Velasco, María y Araujo, Luis. Nómadas no amados. Trayectoria de la nada. Madrid: Primer Acto / El teatro de Papel, 2010.

Velasco, María y Araujo, Luis. Si en el árbol un burka. Vigo: Ediciones Invasoras, 2016.

Velasco, María y Araujo, Luis. "Encantados», en Conejero, Alberto (ed.), A siete pasos del "Quijote», Madrid: Madrid Destino, 2017, pp. 23-28.

Velasco, María y Araujo, Luis. Fuga de cuerpos. Prólogo de Juan Gómez Alemán. Madrid: Antígona, 2017.

Velasco, María y Araujo, Luis. Escenas de caza. Prólogo de Víctor Sánchez Rodríguez. Madrid, Antígona: 2018.

Velasco, María y Araujo, Luis. Los dolores redondos. Escritura, sexo y ambos dos, en Fernández Valbuena, Ana, Las prosopopeyas de María Velasco (Autoficción y teatro), La Rioja: Academia de las Artes Escénicas de España / UNIR: 2018, pp. 159-188.

Zafra, Enriqueta. Prostituidas por el texto: discurso prostibulario en la picaresca femenina. West Lafayette, Indiana: Purdue University Press, 2009.

Zambrano, María. «Lo que le sucedió a Cervantes: Dulcinea». Anthropos ,16, Suplemento «Miguel de Cervantes y los escritores del 27» (1986), pp. 137-148. 


\section{Películas}

Don Quijote, director, Grigor Kozinstev, productora Lenfilm Studio, URSS, 1957.

La mujer del puerto, director, Arturo Ripstein, productora Brooks, EE. UU.-México, 1991.

El hijo de la novia, director, Juan José Campanella, Coproducción Argentina-España; Pol-Ka Producciones / Jempsa / Patagonik Film Group / Tornasol Films. 